\title{
Veterinary Workforce
}

\section{Tips for providing P-12 students career day-type presentations about the veterinary profession}

\author{
Sandra F. San Miguel, DVM, PhD; Amy J. Wackerly, BS; Jennifer H. Veatch, ms; \\ Joseph D. Ruhl, MS; Ann M. Mennonno, MS
}

$\mathrm{C}$ hildren begin forming career aspirations in elementary school, and in many cases, adults find themselves in careers that they decided on before 12 years of age. ${ }^{1-3}$ Tai et $\mathrm{al}^{4}$ report that eighth-grade students who had an expectation of a career in the life sciences were nearly twice as likely to graduate with a baccalaureate degree in the life sciences as were others who did not have that early expectation. Preliminary research has shown that introducing young students to veterinary medicine through formal curricula and activity books can positively impact their attitudes toward and interest in science careers, increase their desire to study science in college, and influence their perceptions of veterinary medicine. ${ }^{5,6}$ And educational experts cite classroom visits by role models and opportunities for role-playing by students as important means for students to learn about careers and the educational requirements needed to attain their occupational choices. ${ }^{2,7}$

Veterinarians and veterinary technicians are frequently invited to participate in career day activities at local schools or community centers. These presentations can provide an opportunity to encourage young students to pursue careers in the veterinary medical profession and provide information about the breadth of opportunities that the profession has to offer. But, for individuals who have not provided presentations in the past, accepting such an invitation can be intimidating. The present report was written by a team consisting of a veterinarian, elementary school teachers, and high school teachers and is intended to provide tips for veterinarians and veterinary technicians planning to visit classrooms or community centers to give career day presentations.

From the Center of Excellence for Diversity and Inclusion in Veterinary Medicine, College of Veterinary Medicine, Purdue University, West Lafayette, IN 47907 (San Miguel); the Center for Inquiry at School 2, 725 N New Jersey St, Indianapolis, IN 46202 (Wackerly); Crawfordsville High School, 1 Athenian Dr, Crawfordsville, IN 47933 (Veatch); Lafayette Jefferson High School, 1801 S 18th St, Lafayette, IN 47905 (Ruhl); and the Center for Inquiry at School 27, 545 E 19th St, Indianapolis, IN 46202 (Mennonno).

Supported by a Science Education Partnership Award from the Office of Research Infrastructure Programs (ORIP), a component of the National Institutes of Health (NIH).

The contents of this article are solely the responsibility of the authors and do not necessarily represent the official views of the ORIP or NIH. Address correspondence to Dr. San Miguel (amasss@purdue.edu).

\section{General Considerations}

Visitor requirements-Many schools and community centers require visitors to complete a volunteer form and undergo a criminal background check and a sex and violent offender registry check before they can visit with minors. Additionally, many schools and community centers will require visitors to sign in and sign out at the main office and use a visitor pass. Some will require visitors to be accompanied by school personnel at all times and might have designated parking areas for visitors. Be sure to ask what requirements and policies you need to follow as a volunteer and guest of the school or community center.

Live animals-Animals can be an excellent means of engaging students, but careful consideration should be given before live animals are brought into a school or community center. First, the school's or center's leaders should be consulted as to whether animals are allowed in the facility. If animals are allowed, the teacher should be consulted to determine whether there are any students or adults in the classroom who have a fear of animals, have allergies to animals, or are immunosuppressed. Next, the type of animals and age of the students should be considered. The ultimate goal is for students to have a positive experience. Some students have an innate fear or have had negative experiences with certain animals. Although positive experiences can help alleviate the fear, you are not likely going to accomplish this during a 20-minute presentation. The temperament of the animal should be considered. For example, a pet dog might be great with children, but might not be great with 30 children. It is recommended that dogs (and other animals as reasonable) be current on all vaccinations and undergo behavioral testing and certification before they are used for educational purposes in a public place. Human health risks that animals might pose should also be assessed. The CDC recommends that reptiles, amphibians, poultry, ferrets, and items these animals have contacted not be handled by children $<5$ years old, senior citizens, or individuals with weakened immune systems. ${ }^{8,9}$

If live animals are allowed in the facility and do not pose a health, safety, or fear risk to students or adults, consider the impact on your presentation. Once an animal is observed, the students' attention will imme- 
diately shift from the content of your presentation to the animal. Decide if and how the information you are delivering can be enhanced by the use of a live animal. Consider revealing the animal toward the end of the presentation, once your talking points have been delivered, to provide an interactive experience or demonstration that positively reinforces the content of your presentation. Remember that student exposure to animals will vary. Be sure to remind students of appropriate ways to interact with the animal before revealing it. Also remember to discuss the importance of hand washing after handling animals and ensure that hand washing occurs after animal contact and before eating. To reduce contamination and reinforce the concept, hand sanitizer can be provided if hand washing is not immediately feasible.

\section{Prepresentation Meeting with the Teacher or Community CenterTeam}

Logistics-It is strongly advised that you contact the teacher or community center team at least 2 weeks before your presentation to arrange a time to meet and discuss your presentation plans. Meeting after regular school-day hours is generally preferred if you are meeting with a teacher. This prepresentation meeting will give you a chance to review logistics, including travel time to the location, parking options, location of the main office, check-in and checkout procedures and time needed to complete these procedures, approval of your background check, location and layout of the classroom or presentation area, audio-visual equipment availability, Internet availability, time allotted for your presentation, and classroom or center rules. The last is important because, as a guest, you do not want to break any rules that students are expected to follow.

Age and experience level-During the prepresentation meeting, you should discuss the content of your presentation. The teacher or center team can help you ensure that the content and type of presentation are appropriate for your audience's age and experience level. For example, a slide presentation might be appropriate for high school students but not desirable for first graders. The teacher or center team can also inform you of what their students already know that is related to your topic. For example, the teacher or center team can help you determine the level of exposure the students have had to animals. Some classrooms and community centers have resident animals (eg, dogs, cats, fish, and rodents) that students see daily. Students might have pets at home. Students might have gone on a trip to the zoo. Keep in mind that experiences in pet ownership and veterinary care might be reduced in communities with a low socioeconomic status.

Cultural relevance-Ask the teacher or center team to describe the demographics of the student population so you can ensure that your presentation is inclusive. Using materials that portray culturally diverse images of veterinary professionals in action and highlighting the accomplishments of culturally diverse veterinary professionals allow all students to see themselves in successful veterinary medical careers. ${ }^{10}$
In traditional African-American and Latino cultures, learning is contextual. Stage setting, or preparing for a task, is an important part of problem solving. ${ }^{10}$ To help set the stage for your presentation, you might provide scrubs, lab coats, or scientific notebooks to use during the presentation. This can encourage excitement about learning.

Research has shown that communal communication and cooperative group learning can facilitate learning by African-American and Latino students. ${ }^{10}$ Communal and cooperative learning is easier to implement in a community center setting than in a formal classroom. Hands-on activities that foster communal learning give the presentation content personal meaning and facilitate mastery by the children. ${ }^{10,11}$ Group activities encourage students to work in partnerships and small heterogeneous groups on learning tasks that have multiple parts. In this way, each group member can contribute to the overall goal. Before any group activities begin, provide students time to introduce themselves to their group members and discuss what they each hope to learn. Lastly, encourage students to write and draw about what they learned after the presentation. Successes can be celebrated by displaying essays and artwork.

Interactive activities-If you are planning interactive activities, determine in advance whether all students will be physically able to participate or what modifications you need to make for the activity to be inclusive. You can let the teacher or center team know if you would like any background information presented to the students in advance of your visit, but should expect to provide them with needed resources.

Get feedback on the safety and appropriateness of items or animals you are planning to bring for students to see or handle. Again, keep in mind that once you give students something, they will be distracted from the presentation. If you are planning on bringing food items such as candy, discuss the appropriateness and ensure none of the items contain ingredients (eg, peanuts) that are allergens for students. If you will be using handouts, ask how many students are in the class so that you can bring sufficient copies or arrange for the teacher to have copies ready.

Room preparation-Discuss the arrangement and setup of the presentation room. The more the teacher or center team knows ahead of time, the more prepared they can be when you arrive. Decide where you want your students to be. Older students might remain at their desks. Younger students might be seated at desks or tables or on a carpet on the floor.

Student management-Managing students during presentations can sometimes be a challenge for visitors. Students who do not know you might test your authority. Similarly, you might not be familiar with the students and any special needs they might have. One way to personalize your presentation is to request that students wear name tags so you can address them by their first names.

Be sure to ask the teacher or staff member in advance whether there are any students with special needs in the group. Students can have visible and invisible disabilities. A group might include a student who uses 
a wheelchair or a student with a cognitive disability. Work with the teacher, student aide, or staff member to ensure that any group activities are inclusive.

Lastly, confirm that a teacher or staff member will be in the room with you at all times and that students with special needs will have a student aide as needed. Your function will be as a content expert and role model. The teacher or staff member in charge should be responsible for assisting with students who are not listening, students who are misbehaving, or students who have needs during the presentation (trips to the bathroom or the nurse). The teacher or staff member can even help with the presentation.

\section{Preparing for the Presentation}

Your presentation should be practiced and polished. Incorporate your passion, enthusiasm, humor, and even a dash of showmanship. Use voice inflection to create drama and excitement in your talk. Teachers are almost like actors on a stage, and you will have to bring some of those qualities to prevent students from becoming bored. Listening to a lecture for 50 minutes from someone they don't know can be difficult for students, and you have to remember you are competing with video games, Instagram, Twitter, Facebook, television, movies, and so on. A wonderful, quick, and easyto-read book that describes effective teaching strategies is entitled Teach Like a Pirate, by Dave Burgess. ${ }^{12}$

Keeping a presentation exciting takes work. Think about the amount of time you are asking students to sit. A good rule of thumb is that student attention span is equal to $1 \mathrm{~min} / \mathrm{y}$ of age (ie, an 8 -year-old can give 8 minutes of attention before needing to move). If you are speaking for $>12$ to 15 minutes, switch your presentation medium to allow for some movement (eg, slides, handouts, artifacts, video clips, games, activities, labs, or demonstrations). Text is not particularly exciting, so if you are using slide presentations, make sure to include color, video clips, pictures, or diagrams. If students participate in movement activities, always begin with rules and consequences for not following the rules so that no one gets hurt.

Asking students questions during the presentation increases student engagement. Your responses to questions should be age appropriate. Avoid saying "no" if an elementary school student gives an incorrect answer. Alternative responses include the following:

- That is not what I was looking for, but I like the way you are thinking.

- Keep thinking, I like how you are trying.

- That is close. Who would like to help?

- I think you were answering but I was going for Do you want another shot at it it, or would you like to call on a friend to help you with this one?

Prizes for correct answers for groups of elementary school students could be distracting. Instead, save giveaway items for students to take home at the end of the presentation.

For high school students, you can improve attention by bringing prizes (candy, pencils, pens, key chains, stickers, etc) to give to students who answer questions correctly, calling on students by throwing a ball to them, or putting their names in a bowl and drawing them to answer questions. Students want to feel as though they are part of the presentation, not just being lectured to. High school students will be held more accountable for the information presented if they know they could be called on.

Attire-Your attire should be neat, clean, and professional and should correspond to the aspect of the veterinary medical profession you are representing. For example, small animal clinicians could wear scrubs or business attire and an examination coat. Large animal clinicians could wear coveralls. Military veterinarians should don their uniform. Researchers can wear a lab coat. A name badge is recommended.

Content-Your presentation should excite students about the breadth of careers in the veterinary profession, inform students of the skills and knowledge they will need to succeed, and explain the steps to becoming a veterinarian. The depth of information provided will depend on the age of your audience. Begin your presentation by introducing yourself and letting the students know the topics you will be discussing. Create dialogue and interactions throughout your talk. Students will learn more when they are engaged in a dialogue rather than listening to a monologue. Ask the students questions and encourage them to ask questions also. As you prepare your content, think about creative ways you can make your presentation interactive. You can even keep a notepad or voice recorder with you to record thoughts immediately so your ideas are not forgotten.

Resources for content can be found online at the AVMA website ${ }^{13}$ and at the Purdue University College of Veterinary Medicine website. ${ }^{14}$

To excite students about the breadth of careers in the veterinary profession, you might consider starting your presentation by finding out what students already know about animals and veterinary medicine, describing the members of the veterinary team, explaining the variety of careers the veterinary profession has to offer, and then asking the students to guess what type of veterinary professional they think you are. For a presentation to elementary school children, you could ask how many have animals at home or how many have visited the zoo. However, you should use these questions simply to gauge the experience level of the group, as asking individual students to tell you about their pets or their visit to the zoo can quickly derail the lesson. First, all students will want to have a chance to tell the group about their animals and animal experiences, and those who do not get the opportunity to do so will feel left out. Second, students who have not had exposure to animals might not feel included in the discussion.

You can, however, call on students in response to questions such as "Do you know what a veterinarian does?" and "Do you know what a veterinary technician does?" Use analogies to human medicine to help students understand the various roles veterinarians can play, explaining that just like human doctors, some veterinarians are family doctors, whereas others are specialists or experts in certain types of animals (dogs, 
cats, horses, cattle, birds, etc) or certain body parts (heart doctors, eye doctors, skin doctors, etc). Describe careers in fields other than clinical practice, such as research and the military.

With this introduction, you can then ask the students to guess what type of veterinary professional they think you are. Call on the students to answer, and give them hints as necessary by suggesting that they look at the way you are dressed or telling them what kinds of animals you work with.

For high school students, you might consider using a slide presentation with images of the veterinary team in action as you describe the breadth of career opportunities. Ensure, however, that your images include individuals of both genders and various races and ethnicity so the students can envision themselves as veterinary professionals.

Once students have identified what type of veterinary professional you are, you can then personalize your presentation by telling them, in a manner the students can relate to, what you might do in a typical day. Telling your personal story helps establish a connection with the students, and students will be more vested in the information you provide. Personalization might also give you credibility on the material you are presenting. As you talk about your work, use anecdotes from your own experiences. Relating information about veterinary medicine to experiences the students may have had can also help improve understanding. Another way to engage students and help them remember information is to involve them emotionally. Both sad and funny stories can be effective, and the "gross" factor can be especially effective for teenagers.

Think about incorporating some items that students can touch and pass around at this time in the presentation. Students love to manipulate things and learn best when they can use all their senses. Students will hear your words, see your slide presentation or handout, and be able to touch the items you brought. Items you could bring to pass around include things you use in your everyday work, such as, for a small animal practitioner, a stethoscope and otoscope; for a dairy practitioner, a balling gun and magnets; and for a surgeon, plates and screws. Other items could include enteroliths, foreign bodies, radiographs, bones, or preserved parasites.

Discuss the skills and knowledge students will need to become a veterinarian or veterinary technician, and explain how students can pursue a career in the veterinary profession. For younger students, this could mean talking about a desire to work with people and animals and a willingness to work hard at school and be a problem solver. For older students, you could focus on specific courses (math, biology, physics, etc) they will need, along with traits they will have to develop, such as good communication, leadership, and problem-solving skills.

Finally, explain the steps necessary to becoming a veterinarian or veterinary technician, including the educational process. For older students, you might also want to talk about the steps needed to become a specialist or researcher.

Questions-Remember to organize your presentation to allow time for students to ask questions, and be prepared for unexpected questions. For elementary school students, you should decide whether you are going to have students hold their questions until the end of the presentation or ask during the presentation. Allowing questions during the presentation can distract other students and interfere with the presentation. Another method is to have students write questions on sticky notes and then choose a few to answer without having to call on anyone.

Some common questions to prepare for include the following:

- How do you help animals?

- How do you give animals medicine?

- What is it like to be a vet?

- Why did you want to be a vet?

For high school students, nothing is more frustrating than when a presenter says, "Hold all questions until the end." Often, time runs short and they never get to ask their question. Allow the presentation to be interactive and dynamic, and use some of the questions to somewhat guide your presentation. Be flexible. It doesn't mean you can't say, "I'll have to take the rest of the questions later" or "We may have time for stories at the end." Some common questions to prepare for include the following:

- What courses should I take in high school?

- What can I do outside of school to prepare?

- What are the salaries of veterinarians and veterinary technicians?

- What grades do I need to be eligible to get into veterinary college?

Feedback-Feedback is important so that you can continually improve your presentations. An easy way to get feedback from elementary school students is to ask them to draw a picture about what they learned from your presentation. High school students can complete a short questionnaire. Examples of questions include the following:

- What did you like most about the presentation?

- What did you like least about the presentation?

- What was the most important thing you learned from the presentation?

\section{Presentation Day}

Allow an extra 15 to 30 minutes in addition to the time you think it will take you to arrive and check in. This will be especially important if you are presenting at the beginning of the day at a school or the end of the day at a community center. Traffic can be a little tedious as school busses are loading and unloading and as parents are dropping off and picking up kids. If you are going to a high school, be especially wary as you will be sharing the road with inexperienced drivers.

Remember that you are the visitor, and respect the authority of the teacher or community center team and their rules while you are a guest. Be flexible. Even though you have thoroughly prepared your presentation, the day may move in a slightly different direction than you originally planned. That is okay. Find ways to make connections with the students to get them mov- 
ing back in the right direction. Don't be afraid to redirect inappropriate student behaviors (like talking to another student while the presenter is talking). Defer to the teacher or community center team member in charge if you are not sure how to answer a question or handle a situation. For elementary school students, find a way to get the students' attention, or ask the teacher how he or she does so. Some suggestions include the following:

- A rhythmic clap.

- A call and response. (You can teach this to students at the beginning of the presentation: " $1,2,3$, eyes on me"; students respond with " 1,2 , eyes on you.")

- Lights out.

- Countdown to 1 .

- Play music. (Let students know ahead of time that when they hear the music, they are to give you their attention.)

Remember to save items for students to keep until the end of the presentation. A nice time to hand out these items is after the feedback forms have been collected.

\section{Academic Standards}

Although there is no core standard that addresses career awareness and education, the English Language Arts Common Core State Standards include speaking and listening standards. ${ }^{15}$ For example, several grade 5 listening and speaking standards ${ }^{15}$ (eg, 5.1: Engage effectively in a range of collaborative discussions... with diverse partners..., building on others' ideas and expressing their own clearly; 5.2: Summarize a written text read aloud or information presented in diverse media and formats, including visually, quantitatively, and orally; and 5.3: Summarize the points a speaker makes and explain how each claim is supported by reasons and evidence) could be applied to a career day presentation.

\section{Conclusion}

Veterinary professionals have the opportunity to influence the future of our profession by being role models for young students and providing them the information and support they need to succeed. By build- ing relationships with schools and community centers and developing presentations for elementary and high school students, they also have an opportunity to broaden participation in the veterinary profession.

\section{References}

1. Trice AD. A retrospective study of career development: I. Relationship among first aspirations, parental occupations, and current occupations. Psychol Rep 1991;68:287-290.

2. Magnuson CS, Starr MF. How early is too early to begin life career planning? The importance of the elementary school years. J Career Dev 2000;27:89-101.

3. Amass SF, Adedokun O, Cipriani Davis K, et al. Mapping our future: developing the pipeline for a diverse workforce. In: Greenhill LM, Cipriani Davis K, Lowrie PM, et al, eds. Navigating diversity and inclusion in veterinary medicine. West Lafayette, Ind: Purdue Press, 2013;55-62.

4. Tai RH, Liu CQ, Maltese AV, et al. Planning early for careers in science. Science 2006;312:1143-1144.

5. San Miguel SF, Burgess W, Cipriani Davis K, et al. Impact of using a veterinary medicine activity book in the classroom on fifth and sixth grade students' depictions of veterinarians. I Vet Med Educ 2013;40:426-430.

6. San Miguel SF, Carleton Parker L, Adedokun O, et al. Fat dogs and coughing horses: K-12 programming for veterinary workforce development. IVet Med Educ 2013;40:419-425.

7. Bobo M, Bertina HL, Durodoye B. Changing patterns in career choices among African-American, Hispanic, and Anglo children. Prof School Couns 1998;1:37-43.

8. CDC website. Reptiles, amphibians, and Salmonella. Available at: www.cdc.gov/features/salmonellafrogturtle. Accessed Feb 4, 2014.

9. CDC website. Animals in schools and daycare settings. Available at: www.cdc.gov/features/salmonellafrogturtle. Accessed Feb 4, 2014.

10. Gay G. Culturally responsive teaching: theory, research, and practice. 2nd ed. New York: Teachers College Press, 2010.

11. Ukpokodu ON. How do I teach mathematics in a culturally responsive way? Identifying empowering teaching practices. Multicult Educ 2011;19:47-56.

12. Burgess D. Teach like a pirate: increase student engagement, boost your creativity, and transform your life as an educator. San Diego: Dave Burgess Consulting Inc, 2012.

13. AVMA website. AVMA tools for K-12 educators. Available at: www.avma.org/kb/k12/pages/avma-educational-resources.aspx. Accessed Feb 4, 2014.

14. Purdue University College of Veterinary Medicine website. Fat dogs and coughing horses: this is how we role. Available at: www.vet.purdue.edu/engagement/sepa. Accessed Feb 4, 2014.

15. Common Core State Standards Initiative website. Implementing the Common Core State Standards. Available at: www.corestandards. org. Accessed Feb 4, 2014. 